\title{
The Influence of Colour Features on Seed Identification Using Machine Vision
}

\author{
Sepideh ANVARKHAH ${ }^{1 *}$, Ali Davari Edalat PANAH², \\ Alireza ANVARKHAH ${ }^{3}$ \\ ${ }^{I}$ Department of Crop Science, Faculty of Agriculture, Ferdowsi University of Mashhad, Mashhad, Iran \\ ${ }^{2}$ Research and Development Center of Astan-e-Qouds, Mashhad, Iran \\ ${ }^{3}$ Azad University of Mashhad, Faculty of Agriculture, Department of Crop Science, Iran; sa_sah_sa25@yahoo.com ("correspondingauthor)
}

\begin{abstract}
Little studies have been done on morphology of medicinal plants seeds. This paper presents an automatic system for medicinal plant seed identification and evaluates the influence of colour features on seed identification. Six colour features (means of red, green and blue colours of the seed surface, as well as means of hue, intensity and saturation) were extracted by algorithm and applied as network input. Different combinations of colour features (one, two three, four, five and six colour features) were used to find out the most accurate combination for seed identification. Results showed that the six colour feature was the most accurate combination for seed identification (99.184\% and $87.719 \%$ for training and test of neural network respectively). One colour feature had the lowest average accuracy values for seed identification (3.120\% and $2.771 \%$ ). In general, increasing the number of colour features increased the total average of accuracy values.
\end{abstract}

Keywords: automatic system, colour grading, hue, medicinal species, seed identification, seed morphology

\section{Introduction}

Although medicinal plants play an important role in the drug industry and health care, and thus draw much attention, few studies have been conducted on their seed identification. Knowledge of seed morphology is important in theoretical botany and could be useful within seed identification for seed testing, seed quarantine, seed dispersal and soil seed bank studies (Jensen, 1995).

Recently, machine vision has become a useful technology for quick seed control and identification (Ureña et al., 2001). Recent advances in hardware and software have enabled machine vision and imaging systems to identify, analyse and display finer details of objects from their digital images (Paliwal et al., 2003).

In laboratories, the most common method for cultivars' identification is to compare morphological characteristics of seeds with standard samples. Such characters include length, width, thickness, shape, weight, hilum colour and seed coat colour (Cope et al., 2012).

Studies showed that colour is a useful characteristic to divide different varieties based on seed coloration such as red-, amber- and white- coloured, but could not be useful for categorizing them into classes (Zhang et al., 2012; Lev-Yadun and Ne'eman, 2013).

Colour is one of the most important features in seeds classification and grading. Different seeds and their varieties are identified by their colours. Thomson and Pomeranz (1991) classified the Western Canadian wheat to six groups using a limited set of colour features (mean red (R), green $(\mathrm{G})$ and blue (B) pixel reflectance features). In general, the red, white and amber coloured wheat types were well separated, while some confusion existed between certain red kernel types. Also, Luo et al. (1999) set an experiment for separation of healthy seeds of Western Canadian wheat from damaged ones using colour features.

Seed colour images might be used also to describe seed quality and hardness, fungal damages, viral diseases, as well as for separating immature seeds apart of mature ones (Ducournau et al., 2004; Liu et al., 2005). In addition, early identification of weed seeds for one crop might be a major interest in the agricultural industry. It can also be useful for chemical control of weed growth (Granitto et al., 2002).

Studies showed that there is a correlation between seed colour and seed quality. For example, it has been reported that the seeds of naturally occurring yellow seeded genotypes $B$. rapa, $B$. juncea and $B$. carinata contained greater oil, higher protein and lower fibre contents than the seeds of black/brown seeded genotypes of these species (Rahman and McVetty, 2011). The yellow seeded Brassica genotypes of these species had a thinner and more translucent seed coat, lower hull proportion with a bigger embryo and consequently greater oil and protein percentage (Rahman and McVetty, 2011). Proanthocyanidins and tannins are the major compounds involved in seed coat pigmentation. These are deposited in the seed coat of black/brown seeded Brassica genotypes and reduce the digestibility of seed meal for livestock. However, the seeds' 
94

coat of black/ brown seeded Brassica genotypes contained more fiber and less protein than those of yellow seeded genotypes. Therefore, $B$. napus lines have been developed from interspecific crosses with related species, namely $B$. rapa, B. oleracea spp. alboglabra, B. juncea and B. carinata (Rahman and McVetty, 2011).

One of the most important attributes for introducing sesame grains in the market was seed colour (Pandey et al., 2013; Zhang et al., 2013). Although most are light coloured, there is a wide variability in sesame seed coat colour, which varies from white to black. Due to the importance of this trait for the export market, seed colour is a central target in sesame breeding programs; however, there are few studies on the inheritance of this essential seed attribute, and determination of genetic factors affecting any trait is necessary to establish useful breeding programs (Laurentin and Benítez, 2014).

Seeds acquire primary dormancy during their development to enhance adaptation, as the capacity of wild species, to diverse environments, by distributing germination over time and space. Domestication tends to reduce dormancy by selection for rapid and uniform germination. Differentiation in seed dormancy between cereal crops and wild relatives has been associated with some factors such as seed morphologies (Guo et al., 2000). For example, the most persistent type of weedy rice is red rice, which is characterized by a red pericarp colour. Red rice has strong seed dormancy (Lim and Ha, 2013). $\mathrm{x}$

In some cases, there is a correlated relationship between seed coat colour and seed quality. Some studies showed that seed lots of red clover visually inspected in terms of seed colour were separated based on a larger colour spectrum thereafter, by digital colour measurement equipment, as seed colour yellow, purple, brown and mixed. Results revealed that seed coat colour of red clover could be preferred as an indicator of seed quality and seedling growth ability. Yellow coloured seeds lots of red clover had higher vigour and seed quality than other colours. Mean germination time (MGT) and electrical conductivity (EC $4 \mathrm{~h}$ ) test showed significant differences among the seed coat colour. Meanwhile, tests also showed a highly significant correlation in emergence and seedling percentage in salt stress conditions (Atis $e t$ al., 2011).

Some seeds are valued according to their appearance, and thus colour is the most important factor for grading (Copeland and McDonald, 2012). The purpose of the current research was to determine the influence of colour features on seed automatic identification.

\section{Materials and Methods}

Grain samples

Seeds from 75 species of medicinal plants (Table 1) were used for this study.

Seeds were photographed using a Dinolite Digital Microscope model 4050 with $640 \times 480$ to $1024 \times 768$ pixel resolution at 30 - to 80 -times magnification, depending on their original size. A database containing 1,800 images of the 75 species was constructed.

\section{Algorithm development}

For algorithm development MATLAB 7.9 (Version 2009b) software and windows Vista (Service Pack 1) were used. Employed hardware was an IBM compatible laptop (model Vostro 1500 from DELL Company). In the algorithm, the seed image was segmented from the background image, and its features were extracted and used for the neural network training (Anvarkhah et al., 2012).

Six colour features were extracted by algorithm and applied as network input:

- Mean of red colour of seed surface (R)

- Mean of green colour of seed surface (G)

- Mean of blue colour of seed surface (B)

- Hue means $(\mathrm{H})$

- Intensity (I)

- Saturation means $(\mathrm{Sa})$

Different combinations of colour features were used to find out the most accurate combination for seed identification.

\section{Results and Discussion}

\section{One colour feature}

Table 2 shows the total average values of training and test parts of neural network, when using each colour feature individually. The use of hue had the highest accuracy values of training and test with values of $9.239 \%$ and $8.771 \%$ respectively. However, employing one colour feature led to a low rate of accuracy values. For example, no accurate identification was shown when using red, blue and saturation features separately $(0 \%)$. The rest of the colour features tested hereby had low accuracy percents, below $8 \%$.

\section{Two Colour Features}

It was noted that two colour features led to a more accurate identification. However, combinations of red, green, blue and saturation with hue caused $0 \%$ of accuracy values, while by using other features paired two by two the results had higher values. The most accurate identification was shown within the combination of hue and intensity, which led to $24.184 \%$ and $19.298 \%$ for training and test parts of neural network respectively (Table 3).

\section{Three colour features}

Table 4 shows the training and test accuracy values obtained by using three colour features within the different colour combinations. Except of two combinations ([red + hue + intensity $], \quad[$ blue + hue + saturation], both with $0 \%$ ), all others had accuracy values of $30-99 \%$ for training and $20-85 \%$ for test parts of neural network.

\section{Four colour features}

Except two combinations of [hue + saturation + red + green] and [hue + saturation + red + blue], all other combinations of four colour features caused above $60 \%$ and $50 \%$ for training and test parts of neural network respectively (Table 5). It seems that using triple effect of 
Table 1. Scientific name and family of the 75 species of medicinal plant seeds used in the experiment

\begin{tabular}{|c|c|c|c|c|c|}
\hline No. & Scientific name & Family & No. & Scientific name & Family \\
\hline 1 & Allium sativum & Alliaceae & 41 & Astragalus siliquosus & Leguminoseae \\
\hline 2 & Amaranthus albus & Amaranthaceae & 42 & Astragalus squarosus & Leguminoseae \\
\hline 3 & Amaranthus retroflexus & Amaranthaceae & 43 & Hedysarum scoparium & Leguminoseae \\
\hline 4 & Anethum graveolens & Apiaceae & 44 & Onobrychis radiata & Leguminoseae \\
\hline 5 & Foeniculum vulgare & Apiaceae & 45 & Onobrychissp. & Leguminoseae \\
\hline 6 & Dorema ammoniacum & Apiaceae & 46 & Securigera securidaca & Leguminoseae \\
\hline 7 & Prangos ferulaceae & Apiaceae & 47 & Allium ampeloprasum persicum & Liliaceae \\
\hline 8 & Achillea millefolium & Asteraceae & 48 & Allium cepa $L$ & Liliaceae \\
\hline 9 & Anthemis tinctoria & Asteraceae & 49 & Allium schoenoprasum $L$. & Liliaceae \\
\hline 10 & Calendula officinalis & Asteraceae & 50 & Linum usitatissimum & Linaceae \\
\hline 11 & Centaurea cyanus & Asteraceae & 51 & Althaea officinalis & Malvaceae \\
\hline 12 & Chrysanthemum superbum & Asteraceae & 52 & Malva dendromorpha & Malvaceae \\
\hline 13 & Cynara scolymus & Asteraceae & 53 & Malva sylvestris & Malvaceae \\
\hline 14 & Pseudohandelia umbellifera & Asteraceae & 54 & Caryophyllus aromaticus & Myrtaceae \\
\hline 15 & Silybum marianum & Asteraceae & 55 & Oenothera biennis & Onagraceae \\
\hline 16 & Echinacea purpurea & Asteraceae & 56 & Sesamum indicum & Pedaliacae \\
\hline 17 & Rudbeckia hirta Marmalade' & Asteraceae & 57 & Digitalis purpurea & Plantaginaceae \\
\hline 18 & Silybum marianum & Asteraceae & 58 & Plantago major & Plantaginaceae \\
\hline 19 & Taraxacum sect & Asteraceae & 59 & Plantago ovata & Plantaginaceae \\
\hline 20 & Borago officinalis & Boraginaceae & 60 & Plantago purshii & Plantaginaceae \\
\hline 21 & Lepidium perfoliatum & Brassicaceae & 61 & Plantago psyllium & Plantaginaceae \\
\hline 22 & Lepidium sativum & Brassicaceae & 62 & Agropyron pectiniforme & Poaceae \\
\hline 23 & Cannabis sativa & Cannabaceae & 63 & Avena sativa & Poaceae \\
\hline 24 & Saponaria officinalis & Caryophyllaceae & 64 & Bromus kopetdaghensis & Poaceae \\
\hline 25 & Erotia ceratoides & Chenopodiaceae & 65 & Hordeum bulbosum & Poaceae \\
\hline 26 & Kochia prostrata & Chenopodiaceae & 66 & Melica persica & Poaceae \\
\hline 27 & Cucurbita pepo & Cucurbitaceae & 67 & Pennisetum orientale & Poaceae \\
\hline 28 & Ricinus communis & Euphorbiaceae & 68 & Portulaca oleracea & Portulacaceae \\
\hline 29 & Fumaria parviflora & Fumariaceae & 69 & Aquilegia vulgaris & Ranunculaceae \\
\hline 30 & Hyssopus officinalis & Lamiaceae & 70 & Nigella sativa & Ranunculaceae \\
\hline 31 & Marrubium vulgare & Lamiaceae & 71 & Ruta graveolens & Rutaceae \\
\hline 32 & Melissa officinalis $\mathrm{L}$. & Lamiaceae & 72 & Physalis alkekengi & Solanaceae \\
\hline 33 & Melissa axillaris (Benth.) Bakh.f. & Lamiaceae & 73 & Hyoscyamus niger & Solanaceae \\
\hline 34 & Ocimum album & Lamiaceae & 74 & Hyoscyamus pusillus & Solanaceae \\
\hline 35 & Ocimum basilicum & Lamiaceae & 75 & Zygophyllum eurypterum & Zygophyllaceae \\
\hline 36 & Origanum majorana & Lamiaceae & & & \\
\hline 37 & Salvia dorrii & Lamiaceae & & & \\
\hline 38 & Salvia sclarea & Lamiaceae & & & \\
\hline 39 & Satureja hortensis & Lamiaceae & & & \\
\hline 40 & Ziziphora clinopodioides & Lamiaceae & & & \\
\hline
\end{tabular}

hue, saturation and red with features of green and blue 100.000 may cause training errors.

\section{Five colour features}

Table 6 shows identification accuracy using five colour features. These combinations led to training and test accuracy values higher than $90 \%$ and $75 \%$ respectively, for all features' combinations.

\section{Six colour features}

The most accurate identification was shown using combination of six colour features $(99.18 \%$ and $87.71 \%$ for training and test of neural network respectively) (Table 7). In general, increasing the number of colour features increased the total average of accuracy (Anvarkhah et al., 2013).

Comparison among colour features combination

Fig. 1 shows the average accuracy values of different

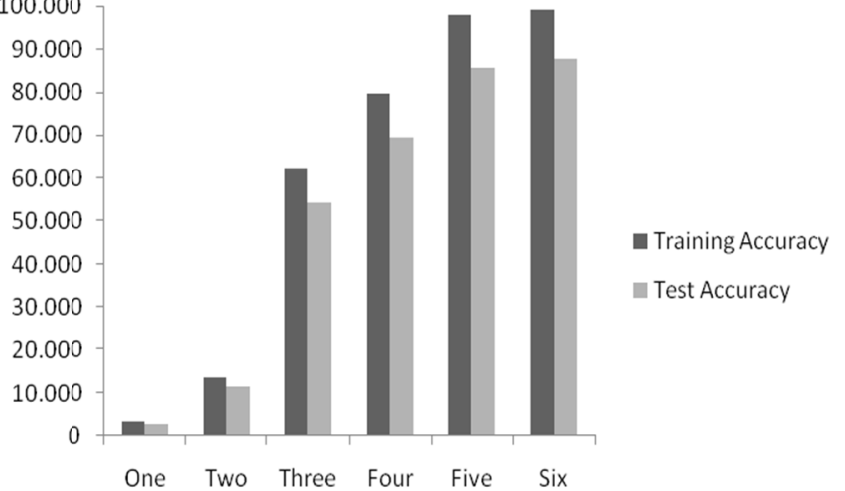

Fig. 1. Average accuracy values using different colour features combinations

colour combinations. Increasing the number of colour features led to higher accuracy values. Combination of six colour features was the most accurate combination with 
96

Table 2. Accuracy values using one colour feature

\begin{tabular}{lcc}
\hline \multicolumn{1}{c}{ Feature } & Training accuracy (\%) & Test accuracy (\%) \\
\hline Green & 3.508 & 4.347 \\
Red & 0 & 0 \\
Blue & 0 & 0 \\
Hue & 9.239 & 8.771 \\
Intensity & 5.978 & 3.508 \\
Saturation & 0 & 0 \\
Average & 3.120 & 2.771 \\
\hline
\end{tabular}

Table 3. Accuracy values using two colour features

\begin{tabular}{lcc}
\hline Feature & Training accuracy (\%) & Test accuracy (\%) \\
\hline Red +Green & 43.070 & 43.859 \\
Green+Blue & 14.402 & 9.649 \\
Red +Blue & 18.750 & 14.035 \\
Red+Hue & 0 & 0 \\
Red+Intensity & 10.597 & 9.649 \\
Red+Saturation & 19.021 & 16.666 \\
Green+Hue & 0 & 0 \\
Green+Intensity & 5.163 & 4.386 \\
Green+Saturation & 20.380 & 16.666 \\
Blue+Hue & 0 & 0 \\
Blue+Intensity & 8.695 & 7.017 \\
Blue+Saturation & 18.206 & 14.035 \\
Hue+Intensity & 24.184 & 19.298 \\
Hue+Saturation & 0 & 0 \\
\hline Intensity+Saturation & 18.750 & 15.789 \\
Average & 13.414 & 11.403 \\
\hline
\end{tabular}

Table 4. Accuracy values using three colour features

\begin{tabular}{|c|c|c|}
\hline Feature & $\begin{array}{l}\text { Training } \\
\text { accuracy } \\
(\%)\end{array}$ & $\begin{array}{c}\text { Test } \\
\text { accuracy } \\
(\%)\end{array}$ \\
\hline Red+Green+Blue & 52.445 & 49.122 \\
\hline Red+Green+Hue & 92.119 & 76.315 \\
\hline Red+Green +Intensity & 32.065 & 28.947 \\
\hline Red +Green Saturation & 91.032 & 80.701 \\
\hline Red + Blue + Hue & 93.750 & 78.070 \\
\hline Red+Blue+Intensity & 33.695 & 32.456 \\
\hline Red+Blue+Saturation & 65.217 & 61.403 \\
\hline Green+Blue+Hue & 78.532 & 68.421 \\
\hline Green+Blue+Intensity & 40.489 & 40.350 \\
\hline Green + Blue + Saturation & 59.782 & 52.631 \\
\hline Red+Hue+Intensity & 0 & 0 \\
\hline Red + Hue + Saturation & 98.641 & 84.210 \\
\hline Red+Intensity+Saturation & 72.282 & 66.666 \\
\hline Green+Hue+Intensity & 55.434 & 44.736 \\
\hline Green + Hue + Saturation & 97.826 & 84.210 \\
\hline Green+Intensity+Saturation & 66.847 & 59.649 \\
\hline Blue+Hue+Intensity & 83.967 & 69.298 \\
\hline Blue + Hue + Saturation & 0 & 0 \\
\hline Blue + Intensity + Saturation & 32.608 & 25.438 \\
\hline Hue+Intensity+Saturation & 97.826 & 84.210 \\
\hline Average & 62.227 & 54.341 \\
\hline
\end{tabular}

accuracy values of $99.184 \%$ and $87.719 \%$ for training and test of neural network. The lowest training and test accuracy values belonged to one colour feature with $3.121 \%$ and $2.771 \%$.

In general, increasing the number of colour features increased the total average of accuracy (Anvarkhah et al., 2013).

Colour is one of the most important features in seeds classification and grading. Different seeds and their varieties are identified by their colours. Thomson and Pomeranz
Table 5. Accuracy values using four colour features

\begin{tabular}{lcc}
\multicolumn{1}{c}{ Feature } & $\begin{array}{c}\text { Training } \\
\text { accuracy } \\
(\%)\end{array}$ & $\begin{array}{c}\text { Test } \\
\text { accuracy } \\
(\%)\end{array}$ \\
\hline Red+Green+Blue+Hue & 98.641 & 85.964 \\
Red+Green+Blue+Intensity & 64.673 & 57.894 \\
Red+Green+Blue+Saturation & 93.206 & 82.456 \\
Hue+Intensity+Saturation+Red & 99.184 & 86.842 \\
Hue+Intensity+Saturation+Green & 98.369 & 82.456 \\
Hue+Intensity+Saturation+Blue & 98.641 & 84.210 \\
Hue+Intensity+Red+Green & 97.282 & 83.333 \\
Hue+Intensity+Red+Blue & 98.097 & 85.964 \\
Hue+Intensity+Green+Blue & 88.858 & 78.947 \\
Hue+Saturation+Red+Green & 0 & 0 \\
\hline Hue+Saturation+Red+Blue & 0 & 0 \\
Hue+Saturation+Green+Blue & 98.641 & 83.333 \\
\hline Intensity+Saturation+Red+Green & 93.478 & 82.456 \\
Intensity+Saturation+Red+Blue & 80.706 & 72.807 \\
Intensity+Saturation+Green+Blue & 85.869 & 75.438 \\
Average & 79.709 & 69.473 \\
\hline
\end{tabular}

Table 6. Accuracy values using five colour features

\begin{tabular}{lcc}
\hline \multicolumn{1}{c}{ Feature } & $\begin{array}{c}\text { Training } \\
\text { accuracy } \\
(\%)\end{array}$ & $\begin{array}{c}\text { Test } \\
\text { accuracy } \\
(\%)\end{array}$ \\
\hline Red+Green+Blue+Hue+Intensity & 98.641 & 86.842 \\
Red+Green+Blue+Hue+Saturation & 99.184 & 87.719 \\
Red+Green+Blue+Intensity+Saturation & 93.206 & 78.947 \\
Hue+Intensity+Saturation+Red+Green & 99.184 & 86.842 \\
Hue+Intensity+Saturation+Red+Blue & 99.184 & 86.842 \\
Hue+Intensity+Saturation+Green+Blue & 98.913 & 85.964 \\
\hline Average & 98.052 & 85.526 \\
\hline
\end{tabular}

Table 7. Accuracy values using six colour features

\begin{tabular}{lcc}
\hline \multicolumn{1}{c}{ Feature } & $\begin{array}{c}\text { Training } \\
\text { accuracy } \\
(\%)\end{array}$ & $\begin{array}{c}\text { Test } \\
\text { accuracy } \\
(\%)\end{array}$ \\
\hline $\begin{array}{l}\text { Red+Green+Blue+Hue+Intensity+ } \\
\text { Saturation }\end{array}$ & 99.184 & 87.719 \\
Average & 99.184 & 87.719 \\
\hline
\end{tabular}

(1991) classified the Western Canadian wheat to six groups using a limited set of colour features (mean Red (R), Green (G) and Blue (B) pixel reflectance features). In general, the red, white and amber coloured wheat types were well separated, while some confusion existed between certain red kernel types. Also, Luo et al. (1999) set an experiment for separation of healthy seeds of Western Canadian wheat from damaged ones using colour features.

\section{Conclusions}

Different combinations of colour features (one, two three, four, five and six colour features) were used to find out the most accurate combination for seed identification by machine vision and algorithm determinations. Results showed that the six colour feature was the most accurate combination for seed identification for training and test of neural network respectively, while employing one colour feature led to a low rate of accuracy values, with a lack of accurate identification when using red, blue and saturation features separately. 


\section{References}

Atiş I, Atak M, Can E, Mavi K (2011). Seed coat color effects on seed quality and salt tolerance of red clover (Trifolium pratense). International Journal of Agriculture and Biology 13(3):363-368.

Anvarkhah S, Hajeh-Hosseini M, Davari-Edalat-Panah A, Rashedmohassel MH (2013). Medicinal plant seed identification using machine vision. Seed Science and Technology 41(1):107120.

Anvarkhah S, Khajeh-Hosseini M, Davari-Edalat-Panah A (2012). Seed identification of ten rangeland species based on machine learning using combination of RBF and Feed Forward neural networks. International Journal of Agriculture and Crop Sciences 4(14):993-1004.

Cope JS, Corney D, Clark JY, Remagnino P, Wilkin P (2012). Plant species identification using digital morphometrics: A review. Expert Systems with Applications 39(8):7562-7573.

Copeland LO, McDonald M (2012). Principles of seed science and technology. Springer Science \& Business Media.

Ducournau S, Feutry A, Plainchault P, Revollon P, Vigouroux B, Wagner MH (2004). An image acquisition system for automated monitoring of germination rate of sunflower seeds. Computer and Electronics in Agriculture 44:189-202.

Granitto PM, Navone HD, Verdes PF, Ceccatto HA (2002). Weed seeds identification by machine vision. Computer and Electronics in Agriculture 33:91-103.

Guo Q, Brown JH, Valone TJ, Kachman SD (2000). Constraints of seed size on plant distribution and abundance. Ecology 81(8):2149-2155.

Jansen PI (1995). Seed production quality in Trifolium balansae and T. resupinatum: The role of seed colour. Seed Science and Technology 23:353-364.

Laurentin H, Benítez T (2014). Inheritance of seed coat color in sesame. Pesquisa Agropecuria Brasiliera 49(4):290-295.
Lev-Yadun S, Ne'eman G (2013). Bimodal colour pattern of individual Pinus halepensis Mill. seeds: a new type of crypsis. Biological Journal of the Linnean Society 109(2):271-278.

Lim SH, Ha SH (2013). Marker development for the identification of rice seed color. Plant Biotechnology Reports 7(3):391-398.

Liu ZY, Cheng F, Ying YB, Rao XQ (2005). Identification of rice seed varieties using neural network. Journal of Zhejiang UniversityScience B 6(11):1095-1100.

Luo X, Jayas DS, Symons SJ (1999). Identification of damaged kernels in wheat using a colour machine vision system. Journal of Cereal Science 30:49-59.

Paliwal J, Visen NS, Jayas DS, White NDG (2003). Cereal grain and dockage identification using machine vision. Biosystems Engineering 85(1):51-57.

Pandey SK, Das A, Dasgupta T (2013). Genetics of seed coat color in sesame (Sesamum indicum L.). African Journal of Biotechnology 12(42):6061.

Rahman M, McVetty PBE (2011). A review of Brassica seed color. Canadian Jounal of Plant Sciences 91(3):437-446.

Thomson WH, Pomeranz Y (1991). Classification of wheat kernels using three dimensional image analysis. Cereal Chemistry 68:357361.

Ureña R, Rodríguez F, Berenguel M (2001). A machine vision system for seeds quality evaluation using fuzzy logic. Computer and Electronics in Agriculture 32(1):1-20.

Zhang H, Miao H, Wei L, Li C, Zhao R, Wang C (2013). Genetic analysis and QTL mapping of seed coat color in sesame (Sesamum indicum L.). PLoS One 8(5):p.e63898.

Zhang X, Liu F, He Y, Li X (2012). Application of hyperspectral imaging and chemometric calibrations for variety discrimination of maize seeds. Sensors 12(12):17234-17246. 